\title{
Acceso al crédito, innovación tecnológica e inserción externa de las empresas argentinas 2010-2012
}

Access to Credit, Technological Innovation and Global

Integration of Argentine Companies 2010-2012

Acesso ao crédito, inovação tecnológica e inserção

externa de empresas argentinas 2010-2012

Leonardo Peñaloza Pacheco*

DOI: https://doi.org/10.19053/01203053.v38.n67.2019.7903

Fecha de recepción: 30 de marzo de 2018

Fecha de aceptación: 15 de noviembre de 2018

Cómo citar este artículo/ To reference this article / Comment citer cet article / Para citar este artigo:

Peñaloza, L. (2019). Acceso al crédito, innovación tecnológica e inserción externa de las empresas argentinas 2010 - 2012. Apuntes del Cenes, 38(67). https://doi.org/10.19053/01203053.v38.n67.2019.7903

* Licenciado en Economía y estudiante de Maestría en Economía de la Facultad de Ciencias Económicas de la Universidad Nacional de La Plata. Buenos Aires, Argentina. leopacheco93@gmail.com (1D https://orcid.org/0000-0003-4863-6422 


\section{Resumen}

Con base en datos de la ENDEI (2010-2012), en este trabajo se analizan las restricciones al crédito que enfrentan las empresas argentinas del sector manufacturero para poder realizar actividades de innovación. Se estiman, empleando MCO, los diferenciales de inversión en innovación entre aquellas firmas que acceden a los créditos bancarios para financiar estas inversiones en comparación con aquellas que no lo hacen, y, luego de controlar por diferentes heterogeneidades de las empresas, se encuentra que aquellas firmas que acceden a los créditos invierten en promedio un $30,74 \%$ más en innovación, siendo este diferencial más acentuado para las empresas de menor tamaño. A su vez, mediante un modelo lineal de probabilidad, se evalúa la relación entre el acceso al crédito y la capacidad de exportación de las empresas. Se obtiene evidencia que indicaría que acceder al crédito para innovar se vincula con una mayor probabilidad de exportar los productos, dado que, según la literatura, existiría una complementariedad entre las inversiones en innovación y la capacidad de exportar de las firmas.

Palabras clave: crédito, $\mathrm{I}+\mathrm{D}$, cambio tecnológico, exportaciones, inversión, Argentina.

Clasificación JEL: O31, O32, F10, E51, G24. 


\section{Abstract}

Based on data from ENDEI (2010-2012) this paper analyzes credit constraints that Argentine companies face to implement innovative activities. The evidence shows that constraints are tighter for SMB compared to big companies. Using OLS we also estimate differentials in investments on innovation between firms that have access to credits to finance their innovation compared to those that are constrained. We find that, after controlling for different characteristics, firms that are not constrained invest $30,74 \%$ more in innovation, on average, than constrained firms. This difference is decrescent with the size of the companies. Finally, using a linear probability model we evaluate the relation between credit access and the likelihood of global integration of Argentine companies. Our findings indicate that having access to credit for investing on innovative activities is related with a higher probability of exporting, which is consistent with theoretical developments that point to the existence of a complementarity between innovative investments and the export ability.

Keywords: credits, R\&D, technological change, exports, investment, Argentina. 


\section{Resumo}

O objetivo deste trabalho é analisar as restrições de crédito das empresas industriais argentinas para investir em inovação com base em dados da ENDEI (2010-2012). Estima-se usando MQO os diferenciais em investimento em inovação entre as empresas que têm acesso a créditos bancários para financiar esses investimentos, em comparação com aquelas que não, encontrando que, após de controlar por diferentes heterogeneidades das empresas, as empresas que têm acesso ao crédito investem, em média, um $30,74 \%$ a mais em inovação, sendo esse diferencial mais acentuado nas pequenas empresas. Além disso, é estimado por um modelo linear de probabilidade a relação entre o acesso ao crédito e a capacidade de exportação das empresas, obtendo evidência que indica que o acesso ao crédito para inovação se relaciona com uma maior probabilidade de exportar os produtos dado que, segundo a literatura, haveria uma complementaridade entre $o$ investimento em inovação e a capacidade das empresas exportarem.

Palavras-chave: Créditos, I \& D, Mudança tecnológica, Exportações, Investimento, Argentina. 


\section{INTRODUCCIÓN}

La inversión en actividades de innovación es uno de los mecanismos que tienen las empresas, independientemente de su tamaño, para mejorar sus capacidades productivas y lograr crecer frente a un mercado cada vez más competitivo (Yoguel $\&$ Boscherini, 2001). A través de esta herramienta, las empresas, en general, diseñan nuevos productos, se insertan en mercados en los que anteriormente no se encontraban, adquieren un posicionamiento con relación al resto de la competencia y disminuyen costos, lo cual les permite ingresar en una senda de crecimiento y desarrollo productivo (Schumpeter, 1939; Medina \& Espinosa, 1994).
Pese a la importancia de la inversión en innovación, contrario a lo argumentado por la teoría neoclásica, los mercados de crédito no son perfectamente competitivos, lo cual genera problemas de asimetrías de información que no permiten el adecuado financiamiento de los proyectos de innovación de las firmas (Stiglitz \& Weiss, 1981). Adicionalmente, existen otros problemas de incentivos que no admiten que las firmas inviertan en este tipo de actividades, debido principalmente a la dificultad para poder apropiarse de los beneficios que genera la inversión (Hall \& Lerner, 2010; Nelson, 1959; Arrow, 1962).

Dado esto, las firmas enfrentan múltiples limitaciones estructurales vinculadas con la capacidad de financiamiento de las actividades de 
innovación, lo cual se explica debido a los elementos particulares de estas inversiones, sobre los cuales se profundizará más adelante.

En el caso de algunos países de América Latina, como Argentina, Chile y México, de acuerdo con la literatura económica, estas restricciones de acceso al crédito para llevar a cabo actividades de innovación tendrían mayor relevancia para las empresas medianas y pequeñas, principalmente porque estas no cuentan con los mismos colaterales ni la misma capacidad de tomar créditos, en comparación con las empresas grandes a las cuales se les facilita mucho más la financiación de los proyectos de inversión (Bebczuk, 2010; Ferraro, 2011).

Por su parte, Hall y Lerner (2010) consideran que este tipo de problemáticas también está presente en economías desarrolladas y centrales (Alemania, Estados Unidos, entre otras), en las cuales las firmas pequeñas se encuentran más restringidas en el mercado crediticio para invertir en innovación que las firmas más grandes y establecidas.

Las limitaciones de acceso al crédito bancario para financiar actividades de innovación no resultarían relevantes si no determinaran diferenciales en las inversiones de este tipo realizadas por las firmas; sin embargo, de acuerdo con la evidencia presentada en este trabajo, existiría una relación positiva entre el acceso al crédito para las pequeñas y medianas empresas en Argentina y los montos invertidos en innovación, no así para las grandes empresas, las cuales aparentemente logran compensar estas restricciones, en caso de existir, con otras fuentes de financiamiento.

A su vez, considerando la hipótesis de complementariedad entre los niveles de productividad de las empresas, la calidad de los productos elaborados y la capacidad de inserción en los mercados extranjeros de las firmas (Verhoogen, 2008), se analiza el impacto que tiene el acceso al crédito para actividades de innovación sobre la probabilidad de que las firmas exporten sus productos, $y$ se encuentra que aquellas empresas que tienen acceso al crédito poseen una mayor probabilidad de exportar sus productos en comparación con aquellas firmas que no tienen dicho acceso.

Esto último resultaría una evidencia importante para trabajar sobre el objetivo de reducir las restricciones en el acceso a los créditos para financiar innovación en la búsqueda de mayores niveles de este tipo de inversiones por parte de las firmas, a fin de que pueda existir, eventualmente, una mayor inserción internacional de la producción de las empresas argentinas.

Teniendo en cuenta lo expuesto, este trabajo se organiza, entonces, de la 
siguiente forma: en la segunda sección se hace una revisión de la literatura vinculada con el financiamiento del cambio tecnológico, de la inversión en general y el impacto sobre la capacidad de exportación de las empresas. En la tercera sección se presenta un breve análisis de los datos vinculados con financiamiento, inversión en actividades de innovación y desempeño exportador de las firmas del sector manufacturero argentino en el periodo 2010-2012, con base en la Encuesta Nacional de Dinámica de Empleo e Innovación (ENDEI) del Ministerio de Ciencia, Tecnología e Innovación Productiva y el Ministerio de Trabajo, Empleo y Seguridad Social de la Argentina. En la cuarta sección se expone evidencia descriptiva con base en los datos de la ENDEI sobre las fuentes de financiamiento de la inversión en innovación de las empresas analizadas. En las secciones quinta y sexta se muestra evidencia econométrica sobre diferenciales en inversión en innovación y en capacidad de inserción externa entre aquellas firmas que acceden al crédito en comparación con las que no lo hacen. $\mathrm{Y}$ en la séptima sección se hacen algunos comentarios finales.

\section{ANTECEDENTES EN LA LITERATURA ECONÓMICA}

De acuerdo con el consenso generalizado en la literatura económica, la innovación es uno de los pilares más significativos en el desarrollo productivo, tanto a nivel microeconómico como macroeconómico, dado que genera las condiciones para el posicionamiento de la economía en su conjunto en la frontera tecnológica, operando como condición necesaria para el desarrollo económico (Vázquez-Barquero, 2000).

Pese a este consenso, aún existen diferentes falencias y restricciones que no permiten que la innovación se pueda realizar en los volúmenes y en las condiciones necesarias para lograr los objetivos deseados. Estas restricciones pueden ser internas, vinculadas con la incapacidad operativa de las empresas de llevar a cabo las actividades de innovación, o bien pueden ser externas. Entre estas últimas, unas de las restricciones exógenas a la innovación son las restricciones de financiamiento de las empresas, las cuales, dado que no cuentan con el crédito suficiente ni los recursos adecuados para llevar a cabo la inversión deseada, ven limitada su capacidad de innovar y de generar ese desarrollo tecnológico.

En primer lugar, es importante tener en cuenta, tal y como Bebczuk (2010) argumenta sobre la baja profundización financiera de la economía argentina, que los créditos bancarios para inversión en Argentina se encuentran concentrados en las empresas más grandes de la economía. De igual 
forma, la misma evidencia indica que el problema de la baja profundización financiera de la economía argentina entre las empresas no es un elemento exclusivamente de oferta de crédito, sino que existen aspectos que hacen que las mismas empresas no se encuentren en condiciones de llevar a cabo la demanda de crédito a las instituciones financieras (Bebczuk, 2010).

Adicionalmente, algunos trabajos, como los de Castillo y Crespo (2011), Hall y Lerner (2010) y Ughetto (2009), enumeran diferentes posibles restricciones inherentes a las inversiones y fundamentalmente vinculadas con las inversiones en actividades de innovación, de las cuales se hará énfasis en dos:

i. La primera restricción que identifica parte de la literatura y la cual será considerada en este análisis, está vinculada con las características propias de este tipo de inversiones, dado que tienen un componente de incertidumbre intrínseco y elementos de temporalidad de la rentabilidad esperada, los cuales hacen que surjan restricciones de financiamiento por parte de las instituciones bancarias a las cuales se les solicita el crédito (Ughetto, 2009).

ii. Otro tipo de restricción existente en los procesos de financiamiento de actividades de innovación está vinculado con las asimetrías de información que hay entre las entidades bancarias y la empresa innovadora (Hall \& Lerner, 2010). Dado que, más allá de ser un ejemplo típico de asimetrías de información que originan racionamiento del crédito (Stiglitz \& Weiss, 1981), las inversiones en innovación tienen un componente intangible que profundiza de alguna manera esta asimetría entre el prestatario y el prestamista, generando mayor incertidumbre por parte de la entidad bancaria y, por lo tanto, mayor propensión a restringir los recursos que son prestados o a exigir colaterales que pueden excluir a las empresas pequeñas del proceso de crédito (Brealey, Leland \& Pyle, 1977).

Las dos restricciones presentadas indican problemas diferentes. La primera restricción, la cual es inherente a cualquier proceso de crédito para realizar actividades de innovación, se vincula con un problema al cual se encuentran expuestas todas las firmas que solicitan préstamos para invertir en innovación independientemente de su tamaño.

Sin embargo, la segunda restricción evidencia un problema al cual se verían más expuestas las empresas medianas y principalmente las empresas pequeñas, dado que serían las que tendrían mayores inconvenientes para 
demostrar a las instituciones bancarias la rentabilidad y garantía de los proyectos en los cuales planean invertir. Esto genera que el sistema bancario incurra en procesos de racionamiento de crédito a este tipo de empresas, para evitar problemas típicos de selección adversa o riesgo moral.

En este trabajo se identifican estos dos tipos de restricciones y se explica de qué manera operan sobre las decisiones de inversión en innovación de las firmas. En primer lugar, se hace un análisis descriptivo de los datos, que permitirá observar la intensidad con la que se usan las diferentes fuentes de financiación, así como los principales motivos por los cuales el sistema financiero no es elegido por parte de las empresas que realizan innovación. En segundo lugar, mediante estimaciones econométricas se muestra si existe algún diferencial entre acceder o no al crédito bancario sobre el gasto que se realiza en innovación por parte de las empresas y si estos diferenciales se mantienen según el tamaño de las firmas.

Adicionalmente, tal y como Verhoogen (2008) argumenta, las firmas que comercializan sus productos en mercados internacionales en general requieren de ciertos niveles de calidad en sus procesos productivos, lo cual se encontraría relacionado con los niveles de inversión en innovación que realicen para mejorar la productividad de la empresa y la calidad de los productos elaborados.

Estos niveles de calidad se encuentran relacionados, por ejemplo, con el tipo de mano de obra contratada por las firmas argentinas. Brambilla, Lederman y Porto (2012) evidencian para el caso argentino que aquellas firmas que exportan sus productos a países de altos ingresos contratan una mayor proporción de empleados altamente calificados, en comparación con firmas que atienden el mercado doméstico o que exportan sus productos a otro tipo de países que no demandan tanta calidad en los productos importados.

Dado esto, es esperable que las firmas que exportan sus productos a los mercados internacionales empleen inputs de mejor calidad en sus procesos productivos. Esta demanda de insumos de mayor calidad estaría vinculada con inversión en actividades de innovación, la cual se podría ver afectada por la existencia de restricciones financieras que no permitan ejecutar los planes de inversión que tienen las firmas.

Por lo tanto, tomando como base la hipótesis de complementariedad de las calidades de Verhoogen (2008) y Kugler y Verhoogen (2008) con sus correspondientes desarrollos empíricos y teóricos, el argumento principal de este trabajo se basa en la idea de que el acceso al crédito podría impactar sobre 
los niveles de inversión en actividades de innovación $\mathrm{y}$, consecuentemente, en la capacidad exportadora de las firmas argentinas como caso particular.

Teniendo en cuenta lo anterior, se debería encontrar evidencia lo suficientemente sólida que fundamente que de existir algún impacto del acceso al crédito sobre los niveles de inversión en innovación que realicen las firmas, entonces también habría un impacto del acceso al crédito sobre la probabilidad de que las firmas exporten sus productos.

Una firma que tenga mayor facilidad para acceder al crédito bancario público o privado, debería, de acuerdo con el planteamiento de este trabajo, poder hacer un mayor gasto en innovación y, por lo tanto, podría acceder a los mercados internacionales con mayor facilidad. Esto se analizará empíricamente en la sexta sección.

\section{DATOS}

El análisis del presente trabajo se realiza con base en datos proporcionados por la Encuesta Nacional de Dinámica de Empleo e Innovación (ENDEI) elaborada por el Ministerio de Ciencia, Tecnología e Innovación Productiva y el Ministerio de Trabajo, Empleo y Seguridad Social de la República Argentina.

Los datos considerados y proporcionados por la ENDEI están vinculados con temas de inversión en innovación de las empresas del sector manufacturero argentino, ingresos y egresos de las firmas, fuentes de financiamiento de las actividades de innovación, alcance geográfico de la red de clientes, y características descriptivas de las empresas argentinas encuestadas para el periodo comprendido por los años 2010,2011 y $2012^{1}$.

En la Tabla 1 se presenta una serie de estadísticos descriptivos para conocer los datos de forma muy general. De acuerdo con esta información, la cantidad de empresas que hicieron parte de la encuesta fue de 3.691, de las cuales el $42,51 \%$ corresponde a empresas pequeñas, el 36,63 \% a empresas medianas y el 20,86 \% a empresas grandes ${ }^{2}$.

Adicionalmente, se puede observar que el $65,97 \%$ de las empresas encuestadas llevaba a cabo actividades

1 En términos de contexto macroeconómico, la actividad económica en el periodo analizado, en general, mantuvo un crecimiento a una tasa promedio trimestral desestacionalizada ligeramente superior al $1 \%$ con caídas en los dos primeros trimestres del año 2012 de acuerdo con datos del INDEC, con lo cual parte de las conclusiones aquí presentadas se deberían analizar bajo un escenario de estabilidad macroeconómica y crecimiento moderado.

2 A partir de ahora en el trabajo, siguiendo la clasificación de la ENDEl, se considerarán pequeñas empresas a las que tienen entre 10 y 25 empleados, empresas medianas a las que tienen entre 26 y 99 empleados y grandes empresas a las que tienen más de 100 empleados. 
de innovación, y entre las que realizaron ese tipo de actividades había una mayor representación de empresas medianas, seguidas de empresas pequeñas y por último de empresas grandes, con una participación sobre el total del $38,15 \%, 34,70 \%$ y $27,15 \%$, respectivamente ${ }^{3}$.

Sin embargo, si el análisis se hace entre empresas de igual tamaño, del total de empresas grandes hay una mayor proporción de empresas del mismo tamaño que realizan actividades de innovación, esto es un 85,84\%; seguidas de las empresas medianas, entre las cuales un $68,71 \%$ de estas lleva a cabo actividades de innovación, siendo las empresas pequeñas las que tienen menos participación de firmas innovadoras, con un 53,86 \%. Esto resulta bastante coherente, dado que las empresas grandes, en su gran mayoría, presentan mayores capacidades que les permiten implementar algunas de las actividades de innovación consideradas.
Por último, según se indica en el primer panel de la Tabla 1, de la totalidad de las firmas encuestadas en la ENDEI durante los años 2010, 2011 y 2012, el $38,85 \%$ de las empresas exporta sus productos. En el segundo y tercer panel de la Tabla 1 se observan estadísticos vinculados con los ingresos en pesos corrientes de las empresas encuestadas y los gastos o inversiones realizados en actividades de innovación.

En valores absolutos, quizá los datos no dicen mucho debido a que contienen un componente inflacionario que, en general, hace inevitable un incremento en los valores corrientes. Sin embargo, al analizar las ventas y el gasto en innovación promedio en comparación con el ingreso y los egresos totales de cada año, respectivamente, se observa que tanto la participación del ingreso por ventas sobre el ingreso total, como la participación del gasto en innovación sobre los egresos totales se mantuvieron estables en el periodo analizado.

3 Las actividades de innovación consideradas de acuerdo con la ENDEl son las siguientes: investigación y desarrollo (I+D) interna, subcontratación de I+D externa, adquisición de maquinarias y equipos, adquisición de hardware y software para innovación, transferencia tecnológica, capacitación para la introducción de innovaciones, consultorías o diseño industrial e ingeniería (interna). 
Tabla 1. Estadísticos descriptivos

\begin{tabular}{lccc}
\hline & $\mathbf{2 0 1 0}$ & $\mathbf{2 0 1 1}$ & $\mathbf{2 0 1 2}$ \\
\cline { 2 - 4 } Número de firmas & 3,691 & 3,691 & 3,691 \\
\cline { 2 - 4 } Pequeñas & 1,569 & 1,569 & 1,569 \\
Medianas & 1,352 & 1,352 & 1,352 \\
Grandes & 770 & 770 & 770 \\
\cline { 2 - 4 } Número de firmas que invierten en tecnología & 2,435 & 2,435 & 2,435 \\
\cline { 2 - 4 } Pequeñas & 845 & 845 & 845 \\
Medianas & 929 & 929 & 929 \\
Grandes & 661 & 661 & 661 \\
\cline { 2 - 4 } Número de firmas que exportan & 1,434 & 1,434 & 1,434 \\
\hline & & & \\
Ventas promedio (pesos corrientes) & $47,061,240$ & $61,238,136$ & $69,207,625$ \\
Gastos en innovación promedio (pesos & $2,062,038$ & $2,959,011$ & $3,146,788$ \\
\hline corrientes) & $96,37 \%$ & $96,40 \%$ & $96,25 \%$ \\
Ingreso por ventas / ingreso total & $5,71 \%$ & $5,21 \%$ & $5,23 \%$ \\
Gastos innovación / egresos totales & & & \\
\hline
\end{tabular}

Fuente: elaboración propia con base en datos de la ENDEI - MINCyT y MTEySS

\section{FUENTES DE}

\section{FINANCIAMIENTO DE}

\section{LA INNOVACIÓN DE LAS EMPRESAS ARGENTINAS}

Lo primero que se puede analizar a partir de lo obtenido de la ENDEI es de qué manera financian las firmas del sector manufacturero las actividades de innovación en la Argentina, independientemente del tamaño o de la rama de actividad de cada una.

De acuerdo con la Figura 1, el 89,87 \% de las firmas se financia con fondos propios en conjunto con cualquier otra forma de financiación de las incluidas en la encuesta. No obstante, el 41,59\% de las empresas se financia exclusivamente con fondos propios; lo que indica que el resto de las firmas utiliza al menos alguna de las otras fuentes de financiación.

Este elemento reafirma lo planteado por la literatura económica sobre el tema de la financiación de la inversión, la cual presenta evidencia que argumenta que las empresas, principalmente medianas y pequeñas, 
financian la inversión en general con fondos propios, bien sea, por ejemplo, mediante utilidades retenidas o algún tipo de aporte por parte de los socios de las compañías, entre otros (Hall \& Lerner, 2010; Bebczuk, 2010).

En esta lista de fuentes de financiamiento, las que tienen una mayor relevancia están vinculadas con el sector financiero privado o público, y la participación de las empresas que utilizan al menos este tipo de financiamiento para invertir en innovación es de un $31,70 \%$ y un $20,99 \%$, respectivamente. Con lo cual resulta notorio que el sector financiero privado juega un rol más importante que el sector público en este tipo de inversiones.

Las otras fuentes, principalmente relacionadas con terceros como los proveedores y los clientes, representan un $17,25 \%$ y un $4,97 \%$ del total de las firmas que innovan; mientras que la mayoría de los programas de financiación de la inversión y la innovación realizados por los entes gubernamentales del nivel nacional, provincial o municipal se encuentra con una participación inferior al $5 \%$.

Adicionalmente, en la Figura 2 se puede observar que hay una mayor proporción de firmas pequeñas que realizan actividades de innovación financiándose exclusivamente con recursos propios, mientras que la banca privada y la pública tienen mayor peso como fuente de recursos entre las firmas grandes.

Estos resultados iniciales evidenciarían que las firmas pequeñas podrían

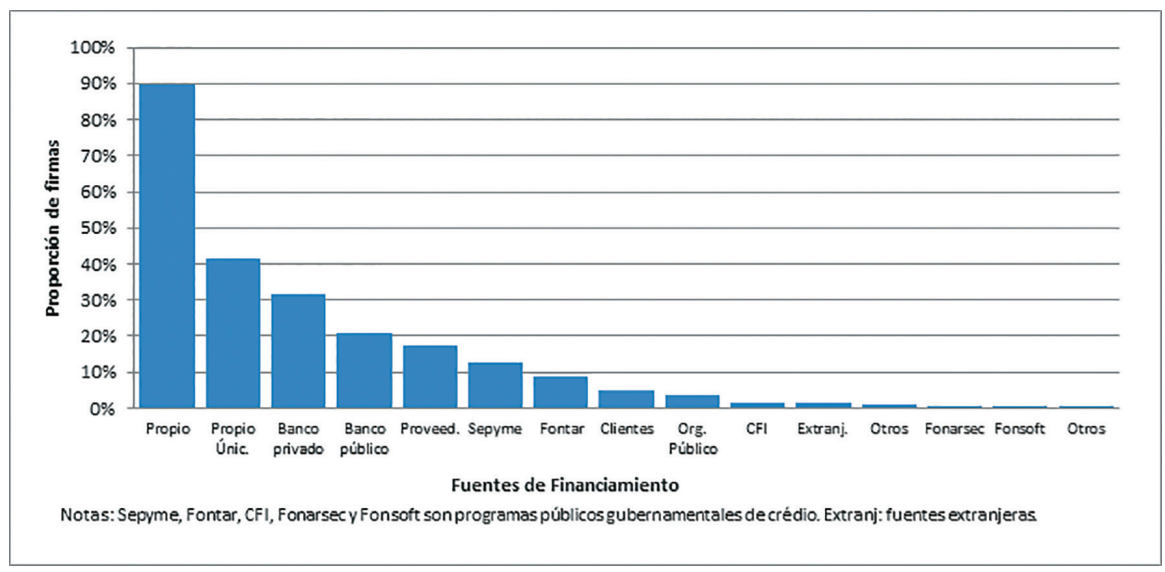

Figura 1. Proporción de firmas por fuentes de financiamiento para actividades de innovación, 2010-2012.

Fuente: elaboración propia con base en datos de la ENDEI-MINCyT y MTEySS 
estar presentando mayores problemas para financiarse por medio del sector financiero, bien sea público o privado.

Esta falta de acceso al crédito bancario por parte de las empresas pequeñas podría ser producto de algún tipo de restricción al financiamiento, porque incluso necesitando los fondos y estando dispuestas a acceder al crédito, son excluidas del sistema financiero, motivo por el cual tienen que acudir en una mayor proporción a los fondos propios para poder llevar a cabo actividades de innovación.

Además, es comprensible que las firmas grandes tengan mayor acceso al crédito financiero, dado que, en general, son parte de grupos empresarios concentrados que generan más confianza al sector bancario $\mathrm{y}$, por lo tanto, mayor disponibilidad de créditos.

Ahora bien, cuando se analiza el conocimiento, el acceso y las limitaciones que tienen las empresas con relación a las fuentes de financiamiento, en la Figura 3 se aprecia que, aproximadamente, entre un $25 \%$ y un $30 \%$ de las firmas encuestadas no conocen fuentes de financiamiento vinculadas con el sector financiero tanto público como privado.

Además, la proporción de firmas que se financiaron por parte del sector privado $(32,74 \%)$ fue mayor que las que lo hicieron accediendo al sector público $(21,68 \%)$, lo cual llama la atención, puesto que los bancos públicos, por su función social, deberían de alguna

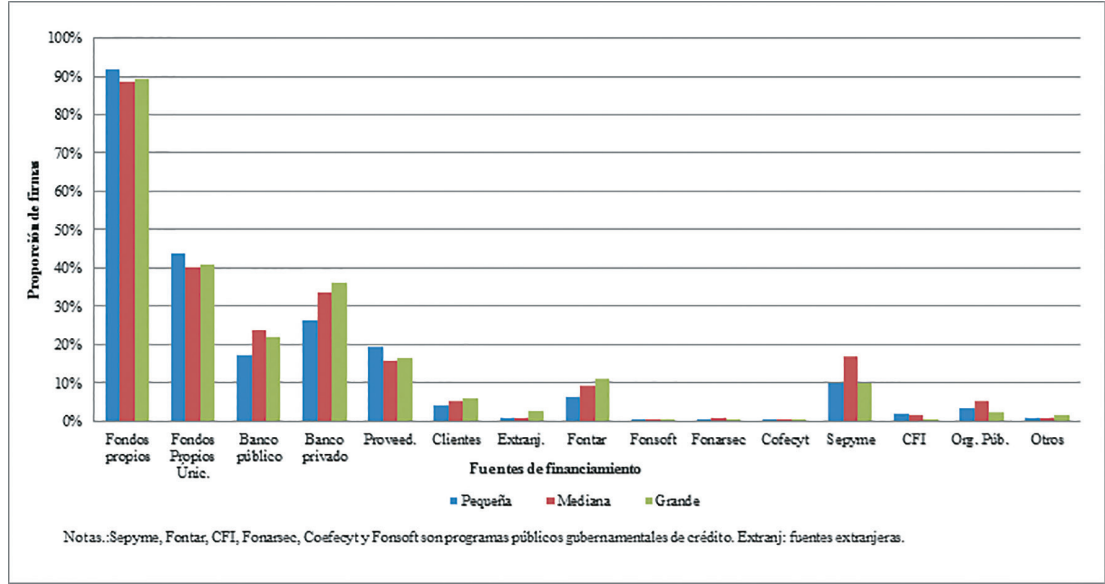

Figura 2. Fuentes de financiamiento por tamaño de firma, 2010-2012.

Fuente: elaboración propia con base en datos de la ENDEI-MINCyT y MTEySS 
forma tener menos restricciones que los bancos privados.

Asimismo, aproximadamente un $40 \%$ de las firmas encuestadas se podría estar autoexcluyendo del financiamiento de las actividades de innovación por parte del sector financiero. Según la información de la Figura 3, el 41,92 \% y el $37,11 \%$ de las firmas no solicitaron créditos a los bancos públicos y privados respectivamente, para financiar las actividades de innovación, pese a conocer las fuentes de financiamiento.

Por último, también es muy extraño el escaso conocimiento de las firmas acerca de los programas públicos como FONTAR, COFECYT, FONARSEC, entre otros. Esto significa un reto para los organismos públicos en términos de difusión de las fuentes de financiamiento a las que pueden acceder las empresas para realizar actividades de innovación.

Cuando el análisis se hace de manera desagregada por el tamaño de la firma, de nuevo los resultados confirman la hipótesis de restricción al crédito en contra de las empresas pequeñas y en favor de las firmas más grandes. Tal y como se puede observar en la Figura 4 , la proporción de firmas grandes que obtienen créditos por parte del sector financiero tanto público como privado es mayor que la proporción de firmas pequeñas que obtienen créditos de la misma fuente de financiamiento,

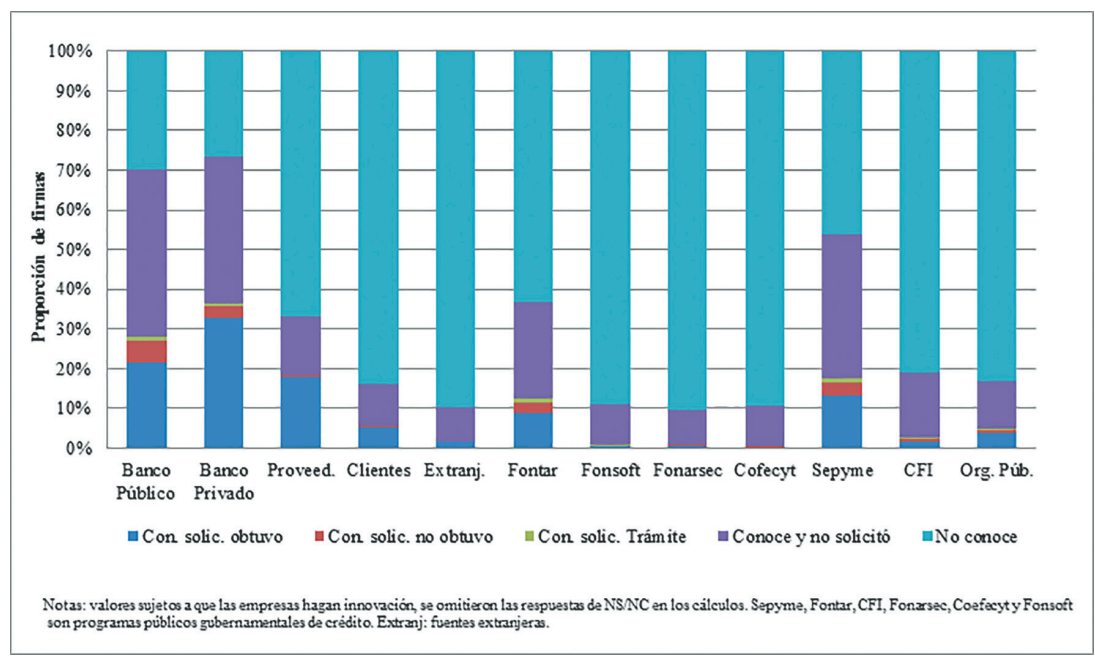

Figura 3. Situación de las empresas con relación a las fuentes de financiamiento, 2010-2012.

Fuente: elaboración propia con base en datos de la ENDEI-MINCyT y MTEySS 
siendo la diferencia mayor entre bancos privados que entre bancos públicos.

De igual forma, la proporción de firmas que solicitaron y no obtuvieron el crédito por parte de bancos públicos o bien por parte de bancos privados es mayor entre las firmas pequeñas que entre las firmas medianas o grandes, siendo de nuevo la diferencia mucho más acentuada en el caso del sector financiero privado que en el caso de los bancos públicos.

Con relación al financiamiento otorgado por terceros, los clientes prestarían mayores servicios de financiamiento a las empresas grandes para realizar actividades de innovación, mientras que los proveedores parecerían estar más dispuestos a brindar ese financiamiento a las empresas pequeñas en comparación con las empresas grandes.

Si este mismo análisis se hace según la composición del capital, la Figura 5 parece evidenciar en general una mayor propensión de las empresas del sector manufacturero con capital exclusivamente nacional a obtener financiación doméstica, bien sea en el sector financiero, a través de organismos públicos o de programas realizados por el Gobierno para impulsar la inversión en tecnología. Esto podría significar que las firmas manufactureras con capital nacional no tienen más opciones que financiarse domésticamente, mientras que las firmas con algún componente de capital internacional sí podrían acceder a algún tipo de financiamiento

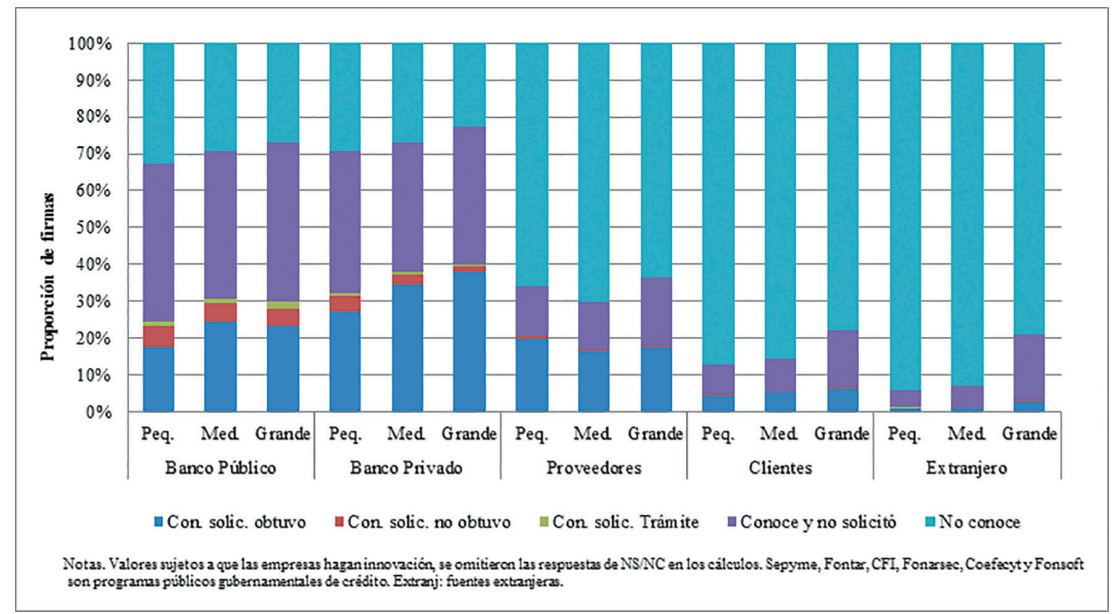

Figura 4. Situación de las empresas con relación a las fuentes de financiamiento por tamaño, 2010-2012.

Fuente: elaboración propia con base en datos de la ENDEI-MINCyT y MTEySS. 


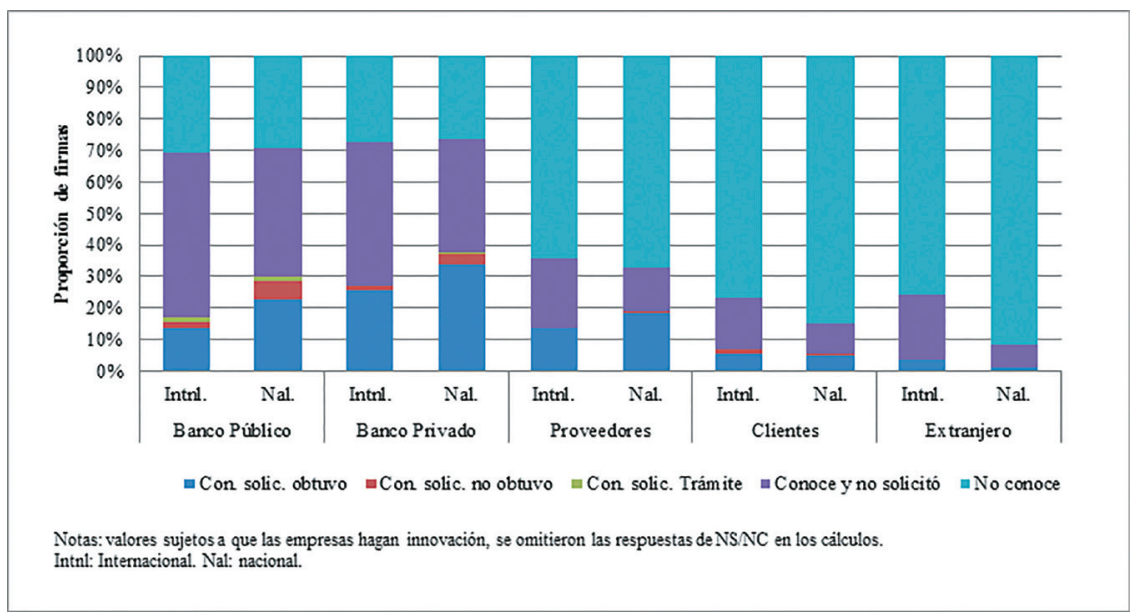

Figura 5. Situación de las empresas con relación a las fuentes de financiamiento por origen del capital, 2010-2012.

Fuente: elaboración propia con base en datos de la ENDEI - MINCyT y MTEySS .

en el extranjero al pertenecer a redes de negocios más globales.

Una vez efectuado un análisis descriptivo de la manera en la que se presenta la financiación de las actividades de innovación por parte de las firmas en Argentina para el periodo estudiado, surge una pregunta relevante para determinar si existe o no algún tipo de restricción al crédito de las pequeñas empresas y que implica analizar los motivos por los cuales aquellas firmas que realizan actividades de innovación no accedieron a los bancos públicos o privados como fuentes de financiamiento para llevar a cabo esa innovación.

En la Figura 6, en primer lugar, se observan los diferentes motivos por los cuales aquellas firmas que llevan a cabo actividades de innovación y que pese a conocer a los bancos públicos o privados como fuentes de financiación, no accedieron al crédito.

En principio, el 16,5\% de las empresas no accedió a los bancos públicos para financiar la innovación debido a las elevadas tasas de interés que estos les ofrecían, sin embargo, la proporción llega casi al doble cuando se trata de bancos privados. Es decir, que un $31 \%$ no accedió a los bancos privados para financiar la innovación porque consideraba que le ofrecía tasas de interés muy elevadas, cifras que evidenciarían mayor hostilidad en términos de costos financieros por parte del sector bancario privado en comparación con el sector bancario público. 
De acuerdo con el Informe de Entidades Financieras del Banco Central de la República Argentina de julio de 2012, en promedio la tasa de interés activa implícita del sector bancario privado en el periodo 2010-2012 fue aproximadamente cuatro puntos porcentuales superior a la del sector bancario público en el mismo periodo. Esta información valida la percepción de las firmas analizadas en la ENDEI vinculada con los elevados costos financieros del sector bancario privado con relación al público.

Adicionalmente, Villar, Briozzo, Pesce y Fernández (2016) analizan los costos financieros para el periodo 2012-2014 y observan que la tasa de interés activa implícita del sector bancario privado es en promedio, en ese periodo, de seis puntos porcentuales superior con relación a la misma tasa del sector bancario público. Esto indicaría que las diferencias en la hostilidad en términos de costos financieros entre los bancos privados y los públicos se ha mantenido en el tiempo.

La situación contraria se presenta cuando las empresas encuestadas no pueden obtener el crédito bancario por la excesiva burocracia. Del total de las empresas, un 15,8\% no accedió al sector bancario privado debido a este motivo y la cantidad casi se duplica cuando se trató de bancos públicos $(29,9 \%)$.

Estos datos demuestran que el sector público impone una excesiva carga burocrática y de trámites para las empresas, que genera demoras en los

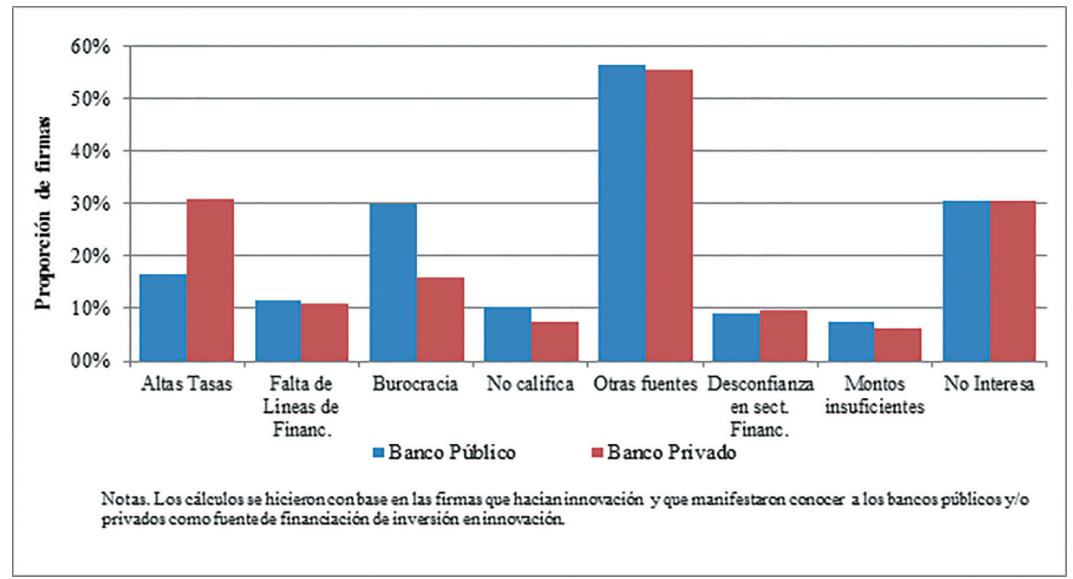

Figura 6. Motivos por los cuales las firmas no accedieron al financiamiento con el sector bancario, 2010-2012.

Fuente: elaboración propia con base en datos de la ENDEI - MINCyT y MTEySS 
trámites de solicitud de financiamiento por parte de las firmas, y un sector bancario privado más flexible en este sentido con las empresas.

Por último, analizando las otras causas, parece haber una leve mayor desconfianza por parte de los empresarios hacia el sector bancario privado frente al sector público. Sin embargo, los bancos públicos, de acuerdo con las firmas analizadas, son más propensos a ofrecer montos insuficientes, dados los requerimientos de crédito y financiamiento por parte de las empresas.

Ahora bien, este mismo análisis se puede hacer de forma análoga, pero desagregando según el tamaño de las empresas, lo cual permitiría evidenciar la posible existencia de algún tipo de restricción al crédito por parte del sector bancario tanto público como privado. Uno de los motivos por los cuales las firmas no accedieron al sector bancario para financiar la innovación, de acuerdo con la Figura 6, son las elevadas tasas de interés, y de acuerdo con la información de la Figura 7 esa percepción es mucho más fuerte entre las empresas pequeñas que entre las empresas grandes, acentuándose más en el caso de los bancos privados.

De esta manera se observa que el $18,64 \%$ de las empresas grandes encuestadas que no accedieron al sector bancario privado, no lo hicieron debido a que consideraban que las tasas de interés eran muy elevadas. Sin embargo, para las empresas pequeñas esta proporción es casi el doble (con un $40,44 \%$ de las firmas), mientras que para el caso de los bancos públicos las diferencias en proporciones entre empresas grandes y pequeñas se mantienen en casi el doble con un 10,66 \% y un $20,68 \%$, respectivamente.

Este dato demuestra dos cosas: en primer lugar, se refuerza el argumento de la mayor hostilidad del sector bancario privado en términos de costos financieros, y el segundo elemento que se obtiene de los datos es que esta hostilidad afecta en mayor medida a las empresas pequeñas en comparación con las grandes, presentando una relación inversa entre el tamaño de la firma y la hostilidad percibida por las empresas en cuanto a los costos financieros.

Tal y como Marshall (2007) y Villar et al. (2016) lo plantean, la banca pública no está sujeta, en general, al mismo proceso de maximización de beneficios que los bancos privados, motivo por el cual pueden otorgar créditos con base en criterios más amplios de beneficios económicos a largo plazo y no únicamente de rentabilidad inmediata, como sucede con los bancos del sector privado.

Esto, por lo tanto, podría explicar la menor hostilidad percibida por parte de las empresas con relación al sector 
bancario público en comparación con el privado. Sin embargo, ese criterio no parece tan flexible cuando se trata de firmas pequeñas, pues estas siguen estando restringidas, incluso por los bancos públicos, aunque en una menor proporción en comparación con el sector bancario privado.

Otro de los motivos que impulsaba a las empresas encuestadas a mostrar desinterés por la financiación con el sector bancario para realizar actividades de innovación, el cual se analizó previamente en agregado, era la excesiva burocracia.

En este caso, cuando se analiza según el tamaño de las empresas, de nuevo el comportamiento es muy parecido al demostrado con las altas tasas de interés como argumento, solamente que en este caso las mayores restricciones provienen, de acuerdo con los datos, del sector bancario público, y el sector privado muestra una mayor flexibilidad, caso contrario a lo que sucede con los costos financieros ${ }^{4}$.

En la Figura 7 se puede observar que con respecto al sector bancario privado, mientras que el $9,75 \%$ de las empresas grandes manifestó que no financió la innovación con bancos privados debido a la excesiva burocracia, esta proporción casi se duplica entre las empresas pequeñas, con una proporción del 19,75\%.

Asimismo, se observa un comportamiento similar, pero en niveles diferentes, para el caso de los bancos públicos, en el cual la proporción de las empresas grandes que afirman que la burocracia es una restricción operativa para obtener los créditos de la innovación por parte de los bancos públicos $(18,75 \%)$ es la mitad en comparación con la proporción entre empresas pequeñas $(36,26 \%)$.

Por otro lado, sobre la desconfianza en el sector financiero, si bien en promedio el sector bancario privado genera mayor desconfianza que el sector público, al desagregar los datos se observa que las empresas pequeñas presentan mayores niveles de desconfianza que las empresas grandes con relación al sector bancario ${ }^{5}$.

En el caso de los bancos privados, un $10,66 \%$ de las empresas pequeñas

\footnotetext{
4 De acuerdo con la ENDEI, la excesiva burocracia en los trámites de solicitud de crédito se vincula con las demoras en la gestión crediticia. Esto es consistente con el hecho de que los tiempos en el sector público, en general, son más extensos en comparación con el privado.

5 Es importante tener en cuenta que la relación entre el público en general y el sector bancario en Argentina ha estado marcada en las últimas dos décadas por problemas de confianza, debido, principalmente, al Corralito y al Corralón ocurrido en el país a fines del periodo de la convertibilidad (2001-2002). Bajo el Corralito y el Corralón se establecieron restricciones a los usuarios del sistema bancario argentino para disponer libremente de sus depósitos, dinero en plazos fijos, cuentas corrientes y cajas de ahorros, lo cual afectó fuertemente la credibilidad del público hacia el sistema financiero.
} 
desconfia del sector financiero privado, frente a un 7,20\% de las empresas grandes que tienen la misma opinión. Cuando se trata de los bancos públicos, la desconfianza de las empresas pequeñas sigue siendo más grande que la de las empresas grandes, con un $11,33 \%$ y un $5,88 \%$ respectivamente.

Adicionalmente, se pueden dilucidar dos cuestiones importantes: por un lado, que la desconfianza es más heterogénea entre las empresas pequeñas y las grandes cuando se trata de bancos públicos que cuando se trata de bancos privados y, por otro lado, que el sector bancario público genera más desconfianza para las empresas pequeñas que el privado, algo que no se presenta a nivel agregado sin considerar el tamaño de la firma.

Además, si bien hay una mayor proporción de empresas pequeñas en comparación con las empresas grandes, que considera que los montos de crédito para actividades de innovación ofrecidos por la banca privada no son suficientes, estas diferencias no son muy profundas. Esto no sucede con la banca pública, en la cual la proporción de empresas pequeñas que considera que los montos ofrecidos por los bancos públicos para financiar innovación son insuficientes $(9,35 \%)$ es casi el doble que la proporción de empresas grandes que consideran lo mismo $(5,51 \%)$

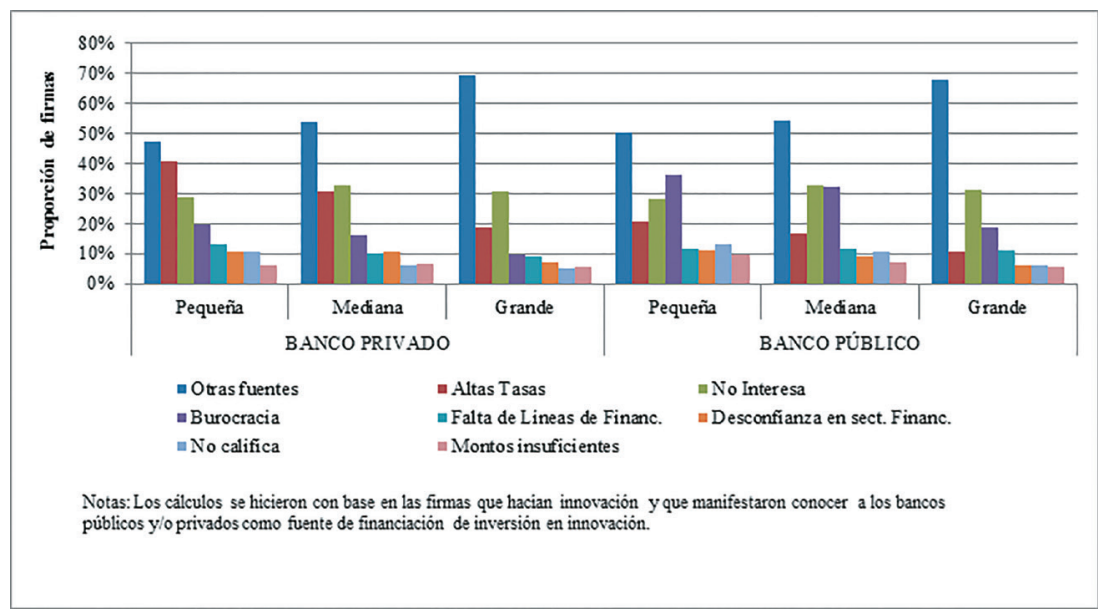

Figura 7. Motivos por los cuales las firmas no accedieron al financiamiento con el sector bancario, por tamaño. 2010-2012.

Fuente: elaboración propia con base en datos de la ENDEI - MINCyT y MTEySS 
Pese a la información presentada hasta el momento, un elemento importante por considerar es que, de acuerdo con la literatura económica especializada, existen algunas firmas que directamente no acuden a los créditos bancarios porque no les interesa o porque no se sienten en las condiciones para obtenerlo, lo cual técnicamente implicaría que no son una demanda real de crédito (Bebczuk, 2010).

Para abarcar este punto, en la Figura 8 se observan los motivos por los cuales las firmas conociendo la fuente de crédito bancario pública o privada $\mathrm{y}$ estando interesadas en obtener el crédito, no lo solicitaron.

De acuerdo con la información de la Figura 8, bien sea debido a los elevados costos financieros o a la excesiva carga burocrática, la proporción de firmas pequeñas excluidas del sistema de crédito público o privado es superior en casi el doble a la de las firmas grandes que no solicitaron financiamiento por los mismos motivos, estando estas firmas interesadas en obtener el crédito.

De igual forma, para el caso de los bancos privados, los montos insuficientes son un problema que perjudica y desincentiva la solicitud de crédito para innovar a todos los tipos de firmas aproximadamente por igual. Sin embargo, para el caso de los bancos públicos este motivo afecta en mayor medida a las empresas pequeñas en comparación con las empresas grandes.

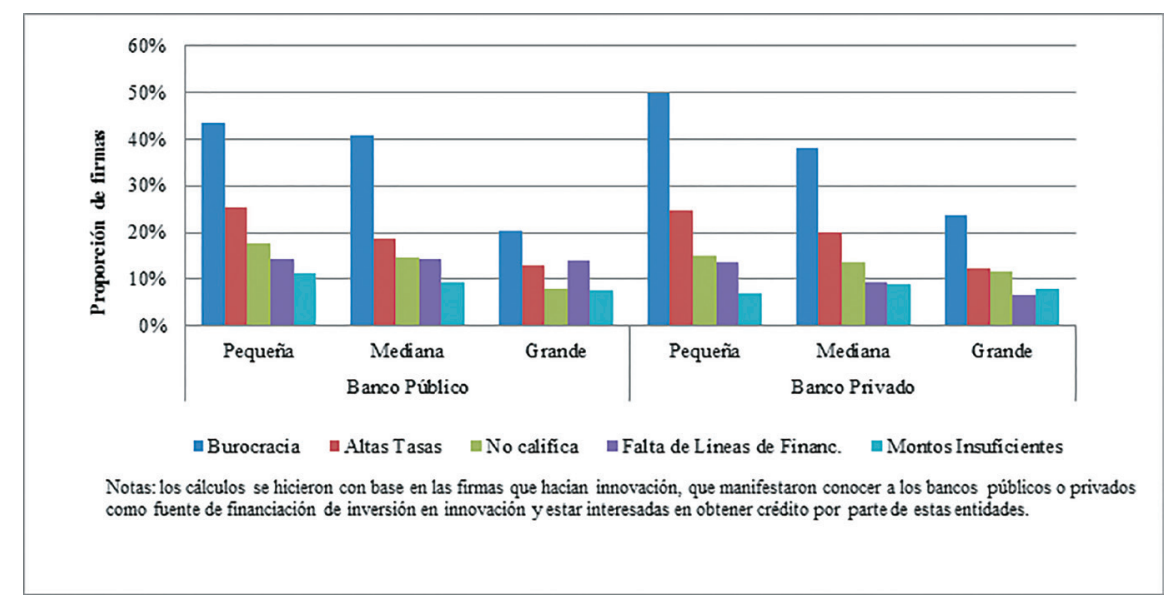

Figura 8. Motivos por los cuales las firmas interesadas en tomar crédito no accedieron al financiamiento con el sector bancario, por tamaño. 2010-2012.

Fuente: elaboración propia con base en datos de la ENDEI - MINCyT y MTEySS. 
Por su parte, la proporción de firmas que no solicitan créditos bancarios al sector financiero público por la falta de líneas de financiamiento es bastante similar, independientemente del tamaño de las empresas, aproximándose a un $14 \%$ en promedio del total de las firmas. Mientras que, para el caso de la banca privada, la proporción de firmas pequeñas que no solicita crédito debido a la falta de líneas de financiamiento es casi el doble que la proporción de firmas grandes.

Los datos presentados, por lo tanto, constituyen evidencia suficientemente sólida como para afirmar que las firmas, en general, financian la mayoría de la inversión en innovación a partir de recursos propios, ocupando un lugar secundario el sector bancario privado y público. A su vez, los programas públicos y los recursos provenientes de organismos gubernamentales no tienen una relevancia muy elevada como fuentes de financiamiento de inversión en innovación.

Adicionalmente, las empresas pequeñas presentan un menor acceso al crédito del sector bancario privado o público en comparación con las empresas medianas y grandes, siendo mucho más relevantes para las pequeñas los recursos propios en comparación con el resto de las empresas.

Por último, también se comprueba en este análisis descriptivo que existen restricciones en el acceso al crédito bancario público o privado para financiar actividades de innovación, tales como las elevadas tasas de interés, la excesiva burocracia, la insuficiencia en los montos disponibles y la falta de líneas de financiamiento que afectan en mayor medida a las empresas pequeñas con relación a las empresas grandes.

En definitiva, se presentó información en esta parte del trabajo que demuestra la mayor hostilidad que tienen que enfrentar las empresas pequeñas en dos situaciones diferentes: la primera, cuando una vez solicitado el crédito, este es negado, pues, como se mostró, hay una mayor proporción de firmas pequeñas a las que no se les otorga el crédito en comparación con las firmas grandes; y la segunda, cuando aquellas firmas que innovan y que se encuentran interesadas en solicitar crédito se enfrentan a mayores restricciones por parte del sector bancario en comparación con las empresas grandes, lo que ocasiona que las firmas pequeñas se inhiban de solicitar los créditos requeridos para llevar a cabo las inversiones en innovación.

\section{INNOVACIÓN Y ACCESO AL CRÉDITO}

Tal y como se presentó en la sección de análisis descriptivo, las empresas pequeñas tienen mayores restricciones al crédito para financiar la innovación. En esta parte del trabajo se estimará si 
las empresas que tienen menos acceso al crédito bancario realizan menores inversiones en actividades de innovación y si, adicionalmente, tales efectos de las restricciones sobre las decisiones de inversión son heterogéneos según el tamaño de las empresas.

Para obtener esta evidencia se estimarán econométricamente las siguientes especificaciones: ${ }^{6}$

$$
\begin{gathered}
\ln (G I)=\alpha+\beta D+X^{\prime} \delta+\varepsilon \\
\ln (G I)^{j}=\alpha+\beta D^{j}+X^{J^{\prime}} \delta+\varepsilon^{j}
\end{gathered}
$$

Donde:

GI: gasto en innovación realizado por la firma en promedio durante el periodo 2010-2012.

$D$ : dummy que vale 1 si la firma conocía la fuente de financiación bancaria pública o privada y obtuvo el crédito para financiar las actividades de innovación, y que vale 0 si la firma conocía la fuente de financiación y no solicitó, o bien, lo solicitó y no obtuvo el crédito?

$X$ : esta variable es un vector de controles que incluyen: controles por rama de actividad de la firma, por composición del capital de las empresas, control que indica si la firma pertenece a un grupo de empresas o no, control por el valor agregado o el ingreso por ventas promedio de la firma en el periodo 2010-2012, controles por tamaño de la firma y controles por tipo de actividad de innovación realizada por la firma.

$\varepsilon$ : error del modelo.

Para el caso del modelo (2), si bien las variables son las mismas, en el vector $\mathrm{X}$ de controles se excluye el control por tamaño de la firma, dado que el supraíndice $j$ indica que se va a realizar la estimación desagregando por tamaño de la firma, para analizar si el efecto del acceso a las fuentes de crédito bancario públicas o privadas se mantiene aún entre firmas del mismo tamaño.

De los resultados de las estimaciones realizadas, el coeficiente de interés es $\beta$ el cual estaría indicando el diferencial promedio en el gasto promedio en innovación realizado entre una firma con acceso al crédito para innovar vis a vis una firma que no tiene acceso al crédito, ceteris paribus. Los resultados de las estimaciones del modelo (1) se presentan en la Tabla 2.

6 Todas las estimaciones econométricas en este trabajo se realizaron mediante mínimos cuadrados ordinarios, corrigiendo los errores estándar por heterocedasticidad. Por lo tanto, dada la metodología implementada, ninguna estimación se puede interpretar de manera causal.

7 Se excluyeron aquellas firmas que a la pregunta de si conocían a los bancos públicos y/o privados como fuente de financiación respondieron que no conocían a la fuente de crédito o bien tuvieron como respuesta No sabe/No Contesta. 
Analizando los resultados de las estimaciones, existe una diferencia positiva y estadísticamente significativa en el gasto realizado en innovación entre aquellas firmas que tienen acceso a créditos financieros en comparación con aquellas firmas que, conociendo las fuentes de financiación, se les negó el acceso o bien no lo solicitaron, resultado que es robusto a diferentes especificaciones y controles incorporados. Luego de controlar por diferentes variables presentadas en la Tabla 2, en promedio, las firmas que acceden al crédito invierten en innovación un $30,74 \%$ más que aquellas firmas que no acceden a las fuentes de financiamiento del sistema bancario público o privado, manteniendo el resto de las variables constantes ${ }^{8}$.

Tabla 2. Gasto en innovación y acceso al crédito

\begin{tabular}{|c|c|c|c|c|}
\hline & \multicolumn{4}{|c|}{ Log Gasto en innovación } \\
\hline & (1) & (2) & (3) & (4) \\
\hline Dummy Acceso al crédito (D) & $\begin{array}{c}0.240 * * * \\
(0.0637)\end{array}$ & $\begin{array}{c}0.291 * * * \\
(0.0631)\end{array}$ & $\begin{array}{c}0.303 * * * \\
(0.0631)\end{array}$ & $\begin{array}{c}0.268 * * * \\
(0.0602)\end{array}$ \\
\hline Log (Valor agregado) & $\begin{array}{c}0.462 * * * \\
(0.0370)\end{array}$ & $\begin{array}{c}0.424 * * * \\
(0.0361)\end{array}$ & $\begin{array}{c}0.412 * * * \\
(0.0362)\end{array}$ & \\
\hline Log (Ingresos) & & & & $\begin{array}{c}0.619 * * * \\
(0.0384)\end{array}$ \\
\hline Dummy Capital nacional & & $\begin{array}{c}-0.833^{* * *} \\
(0.109)\end{array}$ & $\begin{array}{c}-0.684 * * * \\
(0.119)\end{array}$ & $\begin{array}{c}-0.550^{* * * *} \\
(0.106)\end{array}$ \\
\hline Dummy Grupo de empresas & & & $\begin{array}{c}0.336 * * * \\
(0.121)\end{array}$ & $\begin{array}{c}0.217 * * * \\
(0.113)\end{array}$ \\
\hline Número de empresas & 1,778 & 1,778 & 1,778 & 1,845 \\
\hline Control industria & $\mathrm{Si}$ & $\mathrm{Si}$ & $\mathrm{Si}$ & $\mathrm{Si}$ \\
\hline Control tamaño de la firma & $\mathrm{Si}$ & $\mathrm{Si}$ & $\mathrm{Si}$ & $\mathrm{Si}$ \\
\hline Control actividad de innovación & $\mathrm{Si}$ & $\mathrm{Si}$ & $\mathrm{Si}$ & $\mathrm{Si}$ \\
\hline $\begin{array}{l}\text { Notas: variable dependiente: logaritmo del gasto en it } \\
\text { pendientes: Dummy que indica si la firma accedió al } \\
\text { lizara actividades de innovación. Logarittmo del valor } \\
\text { ma para el periodo 2010-2012, Dummy que indica si } \\
\text { grupo de empresa. Debido a la alta correlación entre } \\
\text { cada uno a las variables por separado para evitar prob } \\
\text { tesis. Las estrellas } *, * * \text { y ** indican significativida }\end{array}$ & $\begin{array}{l}\text { realizado por la } \\
\text { ncario público o } \\
\text { o promedio de la } \\
\text { s de capital nacio } \\
\text { gregado de las fir } \\
\text { multicolinealidac } \\
\text { y } 1 \text { por ciento res }\end{array}$ & $\begin{array}{l}\text { a en promedio du } \\
\text { ado sujeta a que co } \\
\text { la para el periodo } \\
\text { exclusivamente, } D \\
\text { y los ingresos }(0 . \\
\text { rores estándar cor } \\
\text { tivamente. }\end{array}$ & $\begin{array}{l}\text { el periodo } 201 \\
\text { era la fuente de } \\
2012 \text {. Logaritt } \\
\text { y que indica s } \\
\text { ee estimaron m }\end{array}$ & $\begin{array}{l}\text { 12. Variables inde- } \\
\text { nciación y que rea- } \\
\text { ingresos de la fir- } \\
\text { ma pertenece a un } \\
\text { ss considerando en } \\
\text { icidad entre parén- }\end{array}$ \\
\hline
\end{tabular}

Fuente: elaboración propia con base en datos de la ENDEI - MINCyT y MTEySS.

8 Es importante tener en cuenta que debido a que de acuerdo con la especificación del modelo, la variable de interés es una dummy y la variable dependiente está en logaritmo, entonces la interpretación del coeficiente estimado no se puede realizar directamente, sino que el efecto marginal es igual a [( $\left.\left.e^{\beta}-1\right) \times 100\right] \%$ 
Una vez analizado el diferencial agregado del gasto en innovación de las firmas, considerando si acceden o no al crédito, también resulta útil realizar el mismo análisis desagregando de acuerdo con el tamaño de las firmas, de manera tal que se pueda observar si este diferencial se sostiene entre empresas del mismo tamaño o si, por el contrario, deja de ser relevante. Para hacer este análisis se estima el modelo (2) presentado previamente.

Los resultados de la estimación se indican en las tablas 3, 4 y 5, cada una correspondiente a los tamaños de las firmas analizadas: pequeñas, medianas y grandes, respectivamente.

Se puede apreciar que de las $1,778 \mathrm{ob}-$ servaciones utilizadas en la estimación del modelo (1), reflejada en la Tabla 2, las empresas pequeñas que componen esa totalidad son 596, las empresas medianas son 707 y las empresas grandes son 475. De igual forma, se hicieron estimaciones incluyendo controles por valor agregado o bien por ingresos de las firmas, por composición del capital de la firma, un control que indique si la firma pertenece o no a un grupo de empresas, controles por rama de actividad de la firma y por tipo de actividad de innovación realizada para evitar cualquier sesgo en los estimadores obtenidos y agregar robustez a los resultados.

De acuerdo con la Tabla 3, el acceso al crédito bancario público o privado en promedio sí tiene una relación positiva con la inversión en innovación para las empresas pequeñas en comparación con otra empresa que no tiene acceso al crédito del mismo tamaño, resultado que es robusto para las diferentes especificaciones.

Después de controlar por rama de actividad y por tipo de actividad de innovación realizada, así como por las otras variables, como el valor agregado/ingresos, la dummy de capital nacional y la de grupo de empresas se observa que aquellas empresas pequeñas que acceden a créditos bancarios para financiar la innovación realizan en promedio un 42,62 \% más de inversión en innovación en comparación con una empresa pequeña que no tiene acceso al crédito bancario público o privado, ceteris paribus.

Tabla 3. Gasto en innovación y acceso al crédito. Firmas pequeñas

\begin{tabular}{lcccc}
\hline & \multicolumn{4}{c}{ Log Gasto en innovación } \\
\hline Dummy Acceso al crédito (D) & $\mathbf{( 1 )}$ & $\mathbf{( 2 )}$ & $\mathbf{( 3 )}$ & $\mathbf{( 4 )}$ \\
& $0.340^{* * *}$ & $0.347^{* * *}$ & $0.355^{* * *}$ & $0.299^{* * *}$ \\
& $(0.0951)$ & $(0.0943)$ & $(0.0941)$ & $(0.0879)$ \\
\hline
\end{tabular}


Continuación Tabla 3.

\begin{tabular}{|c|c|c|c|c|}
\hline & \multicolumn{4}{|c|}{ Log Gasto en innovación } \\
\hline & (1) & (2) & (3) & (4) \\
\hline Log (Valor agregado) & $\begin{array}{c}0.404 * * * \\
(0.0570)\end{array}$ & $\begin{array}{c}0.400 * * * \\
(0.0566)\end{array}$ & $\begin{array}{c}0.384 * * * \\
(0.0567)\end{array}$ & \\
\hline Log (Ingresos) & & & & $\begin{array}{c}0.708 * * * \\
(0.0617)\end{array}$ \\
\hline Dummy Capital nacional & & $\begin{array}{c}-0.709 * * * \\
(0.232)\end{array}$ & $\begin{array}{c}-0.579 * * * \\
(0.219)\end{array}$ & $\begin{array}{c}-0.429 * * \\
(0.170)\end{array}$ \\
\hline Dummy Grupo de empresas & & & $\begin{array}{c}0.581 * * * \\
(0.193)\end{array}$ & $\begin{array}{c}0.377 * * \\
(0.180)\end{array}$ \\
\hline Número de empresas & 596 & 596 & 596 & 627 \\
\hline Control Industria & $\mathrm{Si}$ & $\mathrm{Si}$ & $\mathrm{Si}$ & $\mathrm{Si}$ \\
\hline Control Actividad de innovación & $\mathrm{Si}$ & $\mathrm{Si}$ & $\mathrm{Si}$ & $\mathrm{Si}$ \\
\hline \multicolumn{5}{|c|}{$\begin{array}{l}\text { Notas: variable dependiente: logaritmo del gasto en innovación realizado por la firma en promedio durante el periodo 2010-2012. Variables inde- } \\
\text { pendientes: Dummy que indica si la firma accedió al crédito bancario público o privado sujeta a que conociera de la fuente de financiación y que } \\
\text { realizara actividades de innovación. Logaritmo del valor agregado promedio de la firma para el periodo } 2010-2012 \text {. Logaritmo de ingresos de la } \\
\text { firma para el periodo } 2010-2012 \text {, Dummy que indica si la firma es de capital nacional exclusivamente, Dummy que indica si la firma pertenece a } \\
\text { un grupo de empresas. Debido a la alta correlación entre el valor agregado de las firmas y los ingresos (0.89), se estimaron modelos consideran- } \\
\text { do en cada uno a las variables por separado para evitar problemas de multicolinealidad. Errores estándar corregidos por heterocedasticidad entre } \\
\text { paréntesis. Las estrellas } * * * \text { y ** indican significatividad al } 10,5 \text { y } 1 \text { por ciento respectivamente. }\end{array}$} \\
\hline
\end{tabular}

Fuente: elaboración propia con base en datos de la ENDEI - MINCyT y MTEySS.

Para el caso de las empresas medianas, las estimaciones arrojan resultados similares, según los cuales, tal y como se observa en la Tabla 4, la mayor inversión en innovación realizada cuando se tiene acceso al tipo de crédito bajo análisis es en promedio del $35,53 \%$, manteniendo el resto de las variables constantes, en comparación con una empresa mediana que no tiene acceso al crédito bancario público o privado.

Tabla 4. Gasto en innovación y acceso al crédito. Firmas medianas

\begin{tabular}{lcccc}
\hline & \multicolumn{3}{c}{ Log Gasto en innovación } \\
\hline Dummy Acceso al Crédito (D) & $\mathbf{( 1 )}$ & $\mathbf{( 2 )}$ & $\mathbf{( 3 )}$ & $\mathbf{( 4 )}$ \\
& $0.279^{* * *}$ & $0.304^{* * *}$ & $0.304^{* * *}$ & $0.271^{* * *}$ \\
Log (Valor agregado) & $(0.103)$ & $(0.102)$ & $(0.102)$ & $(0.968)$ \\
& $0.336^{* * *}$ & $0.321^{* * *}$ & $0.316^{* * *}$ & \\
Log (Ingresos) & $(0.0635)$ & $(0.0628)$ & $(0.0627)$ & \\
& & & & $0.533 * * *$ \\
Dummy Capital nacional & & $-0.818^{* * *}$ & $-0.684 * * *$ & $-0.456^{* *}$ \\
& & $(0.172)$ & $(0.184)$ & $(0.146)$ \\
Dummy Grupo de empresas & & & $0.405^{* *}$ & $0.377^{*}$ \\
\hline
\end{tabular}


Continuación Tabla 4.

\begin{tabular}{|c|c|c|c|c|}
\hline & \multicolumn{4}{|c|}{ Log Gasto en innovación } \\
\hline & (1) & (2) & (3) & (4) \\
\hline & & & $(0.203)$ & $(0.182)$ \\
\hline Número de empresas & 707 & 707 & 707 & 729 \\
\hline Control industria & $\mathrm{Si}$ & $\mathrm{Si}$ & $\mathrm{Si}$ & $\mathrm{Si}$ \\
\hline Control actividad de innovación & $\mathrm{Si}$ & $\mathrm{Si}$ & $\mathrm{Si}$ & $\mathrm{Si}$ \\
\hline \multicolumn{5}{|c|}{ 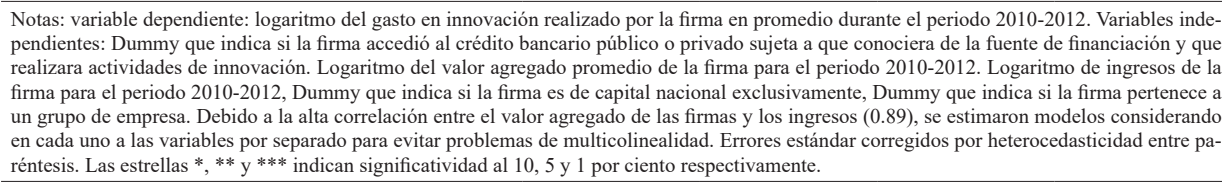 } \\
\hline
\end{tabular}

Fuente: elaboración propia con base en datos de la ENDEI-MINCyT y MTEySS.

Ahora bien, de acuerdo con los coeficientes estimados y presentados en la Tabla 5, para las firmas grandes no parece haber un diferencial estadísticamente significativo en la inversión en innovación, explicado por el acceso al crédito por parte del sector bancario, estimación que es robusta para las diferentes especificaciones.

Este resultado podría interpretarse debido a la mayor posibilidad que tienen las firmas grandes de financiarse tanto con recursos propios como con recursos provenientes de otras fuentes, domésticas o internacionales, que les permiten obtener los fondos necesarios para llevar a cabo las inversiones en innovación que requieren.

Por lo tanto, a medida que las firmas aumentan de tamaño, el efecto del acceso al crédito bancario va perdiendo relevancia como determinante del gasto en innovación realizado por las empresas.

Tabla 5. Gasto en innovación y acceso al crédito. Firmas grandes

\begin{tabular}{lcccc}
\hline & \multicolumn{4}{c}{ Log Gasto en innovación } \\
\hline Dummy Acceso al crédito (D) & $(\mathbf{1})$ & $\mathbf{( 2 )}$ & $\mathbf{( 3 )}$ & $\mathbf{( 4 )}$ \\
& 0.0629 & 0.175 & 0.190 & 0.161 \\
Log (Valor agregado) & $(0.146)$ & $(0.145)$ & $(0.148)$ & $(0.144)$ \\
& $0.562^{* * *}$ & $0.500^{* * *}$ & $0.493 * * *$ & \\
Log (Ingresos) & $(0.0699)$ & $(0.0686)$ & $(0.0687)$ & \\
& & & & $0.677 * * *$ \\
Dummy Capital nacional & & & & $(0.0752)$ \\
\hline
\end{tabular}


Continuación Tabla 5.

\begin{tabular}{|c|c|c|c|c|}
\hline & \multicolumn{4}{|c|}{ Log Gasto en innovación } \\
\hline & (1) & (2) & (3) & (4) \\
\hline & & $(0.179)$ & $(0.209)$ & $(0.197)$ \\
\hline Dummy Grupo de empresas & & & $\begin{array}{c}0.156 \\
(0.203)\end{array}$ & $\begin{array}{l}0.0261 \\
(0.182)\end{array}$ \\
\hline Número de empresas & 475 & 475 & 475 & 489 \\
\hline Control industria & $\mathrm{Si}$ & $\mathrm{Si}$ & $\mathrm{Si}$ & $\mathrm{Si}$ \\
\hline Control actividad de innovación & $\mathrm{Si}$ & $\mathrm{Si}$ & $\mathrm{Si}$ & $\mathrm{Si}$ \\
\hline $\begin{array}{l}\text { Notas: variable dependiente: logaritmo del gasto en } \\
\text { pendientes: Dummy que indica si la firma accedió al } \\
\text { realizara actividades de innovación. Logaritmo del } \\
\text { firma para el periodo } 2010-2012 \text {, Dummy que indica } \\
\text { un grupo de empresas. Debido a la alta correlación e } \\
\text { do en cada uno a las variables por separado para evit } \\
\text { paréntesis. Las estrellas *, ** y*** indican significa }\end{array}$ & $\begin{array}{l}\text { de capitato } \\
\text { gregado } \\
\text { le multi }\end{array}$ & $\begin{array}{l}\text { n promedio } \\
\text { o sujeta a que } \\
\text { a para el per } \\
\text { exclusivamen } \\
\text { sy y los ingre } \\
\text {. Errores est }\end{array}$ & $\begin{array}{l}\text { el periodo } 20 \\
\text { erar de la fun } \\
10-2012 \text {. Log } \\
\text { nyy que indic } \\
\text { 9), se estimar } \\
\text { orregidos por }\end{array}$ & $\begin{array}{l}\text { Variables inde } \\
\text { nanciación y qu } \\
\text { de ingresos de } 1 \\
\text { firma pertenece } \\
\text { lelos consideran } \\
\text { edasticidad entr }\end{array}$ \\
\hline
\end{tabular}

Fuente: elaboración propia con base en datos de la ENDEI-MINCyT y MTEySS.

\section{INSERCIÓN EXTERNA Y ACCESO AL CRÉDITO}

En esta sección se estudiarán las consecuencias que tiene la restricción al acceso al crédito sobre la capacidad de inserción externa de las empresas.

En este sentido, según lo estudiado por Brambilla y Peñaloza (2018), existe evidencia obtenida a partir del procesamiento de los mismos datos de la ENDEI, según la cual aquellas empresas que exportan sus productos, en general, tienen más probabilidad de efectuar actividades de innovación.

Incluso cuando se considera el gasto en innovación que realiza una firma que exporta en comparación con una que no exporta, la evidencia indica que, en promedio, las firmas que exportan invierten un $36 \%$ más en innovación en comparación con las firmas que no exportan, manteniendo el resto de las variables constante y controlando por industria, tamaño de la empresa y origen del capital.

Por lo tanto, en este mismo sentido, una restricción que opere sobre el crédito, como vimos previamente (tablas 3 y 4), hace que las firmas pequeñas y medianas en promedio inviertan un $42,62 \%$ y un $35,53 \%$ menos en actividades de innovación respectivamente. Esto generaría, según Brambilla y Peñaloza (2018) y Verhoogen (2008), una reducción en la capacidad de las firmas pequeñas y medianas de insertarse en el comercio internacional, explicada fundamentalmente porque las exportaciones requieren productos $\mathrm{y}$ servicios de calidad, debido a que en el comercio internacional, en general, los países demandan productos de cierta 
calidad y complejidad que necesitan inversión en innovación por parte de las empresas.

Para fundamentar este vínculo entre acceso al crédito y capacidad de inserción externa de la producción de las empresas, en esta sección se analiza econométricamente la relación que tienen el acceso al crédito y la probabilidad de exportar de una empresa, con base en el modelo lineal de probabilidad que se presenta a continuación:

$$
E=\alpha+\beta D+X^{\prime} \delta+\epsilon
$$

Donde:

E: es una variable dummy que toma valor igual a 1 si la firma exporta sus productos y que vale 0 en caso contrario. ${ }^{9}$

D: dummy que vale 1 si la firma tiene acceso al crédito bancario público o privado sujeta a que conozca la fuente de financiación y que realice actividades de innovación y que vale 0 en caso contrario $^{10}$.
$\mathrm{X}$ : vector de controles que incluyen: controles por el valor agregado de la firma promedio para el periodo 20102012, controles por rama de actividad de la firma, controles por tamaño de la firma, una variable que controla por si la firma pertenece a un grupo de empresas o no, controles por composición del capital y controles por tipo de actividad de innovación realizada por la firma ${ }^{11}$.

$\epsilon$ : error del modelo.

De acuerdo con los resultados de estimación del modelo (3) en la Tabla 6, la probabilidad de que una firma exporte es mayor cuando tiene acceso al crédito que cuando no lo tiene, efecto que es robusto a medida que vamos controlando por diferentes heterogeneidades. Esta evidencia refuerza lo planteado en párrafos anteriores, siguiendo el argumento de Verhoogen (2008), los resultados obtenidos por Brambilla y Peñaloza (2018) y las estimaciones presentadas en las tablas 2, 3 y 4 del presente trabajo, con base en los datos de la ENDEI.

9 El alcance geográfico de la red de clientes reportado por las firmas que exportaban está compuesto por países del Mercosur (Brasil, Paraguay y Uruguay), otros países de América Latina, Estados Unidos, Canadá, Europa, Asia, África y Oceanía.

10 Se excluyeron aquellas firmas que a la pregunta de si conocían a los bancos públicos y/o privados como fuente de financiación respondieron que no conocían la fuente de crédito o bien tuvieron como respuesta No sabe/No Contesta.

11 El control por la composición del capital de la empresa permite diferenciar aquellas firmas cuyo capital es exclusivamente nacional de aquellas cuyo capital tiene un componente internacional. Para controlar por tamaño de la firma se usó una dummy que tomará valor 1 si era una empresa grande y 0 en caso contrario. 
Tabla 6. Acceso al crédito e inserción externa de las firmas

\begin{tabular}{|c|c|c|c|c|c|c|c|}
\hline & \multicolumn{7}{|c|}{ E (=1 si la firma exporta) } \\
\hline & (1) & (2) & (3) & (4) & (5) & (6) & (7) \\
\hline \multirow[t]{2}{*}{ Dummy Acceso al crédito (D) } & $0.0405^{*}$ & $0.0555^{* *}$ & $0.0600^{* * *}$ & $0.0635^{* * *}$ & $0.0440 * *$ & $0.0385^{*}$ & $0.0377 *$ \\
\hline & $(0.0232)$ & $(0.0230)$ & $(0.0228)$ & $(0.0224)$ & $(0.0218)$ & $(0.0219)$ & $(0.0222)$ \\
\hline \multirow[t]{2}{*}{ Dummy Capital nacional } & & $-0.285 * * *$ & $-0.168 * * *$ & $-0.144 * * *$ & $-0.0943 * * *$ & $-0.0822 * *$ & $-0.0920^{* *}$ \\
\hline & & $(0.0331)$ & $(0.0398)$ & $(0.0402)$ & $(0.0380)$ & $(0.0384)$ & $(0.0394)$ \\
\hline \multirow[t]{2}{*}{ Dummy Grupo de empresas } & & & $0.209^{* * *}$ & $0.191 * * *$ & $0.0824 * *$ & $0.0774 * *$ & 0.0589 \\
\hline & & & $(0.0369)$ & $(0.0375)$ & $(0.0374)$ & $(0.0379)$ & $(0.0388)$ \\
\hline \multirow[t]{2}{*}{ Log (Valor agregado) } & & & & & & & $0.0463 * * *$ \\
\hline & & & & & & & $(0.0105)$ \\
\hline Número de empresas & 1,853 & 1,853 & 1,853 & 1,853 & 1,853 & 1,853 & 1,778 \\
\hline Control industria & No & No & No & Sí & Sí & Sí & Sí \\
\hline Control tamaño & No & No & No & No & Sí & Sí & Sí \\
\hline \multicolumn{8}{|c|}{$\begin{array}{l}\text { Notas: variable dependiente: dummy que indica si la firma exporta. Variables independientes: dummy que indica si la firma accedió al crédito ban- } \\
\text { cario público y/o privado, sujeta a que conociera de la fuente de financiación y que realizara actividades de innovación. Logaritmo del valor agre- } \\
\text { gado promedio de la firma para el periodo } 2010.2012 \text {, dummy que indica si la firma es de capital nacional exclusivamente, dummy que indica si la } \\
\text { firma pertenece a un grupo de empresa. Errores estándar corregidos por heterocedasticidad entre paréntesis. Las estrellas *, ** y*** indican sig- } \\
\text { nificatividad al } 10,5 \text { y } 1 \text { por ciento respectivamente. }\end{array}$} \\
\hline
\end{tabular}

Fuente: elaboración propia con base en datos de la ENDEI-MINCyT y MTEySS.

\section{CONCLUSIONES}

Si bien existe un consenso generalizado sobre los beneficios que tiene la inversión en innovación para las empresas y el impacto que esta tiene en el desarrollo de las economías, principalmente en las periféricas, en este trabajo se mostró que en Argentina, de acuerdo con la evidencia obtenida, hay limitaciones que no permiten a las empresas del sector manufacturero realizar actividades de innovación o incrementar los montos de las inversiones que realizan en términos de transformación tecnológica.

Una de esas limitaciones analizadas es el acceso al crédito, principalmente de bancos públicos o privados, sobre el cual parecen existir restricciones que afectan a las empresas medianas $\mathrm{y}$ en mayor medida a las empresas pequeñas.

Estas restricciones de financiamiento, por su parte, generan desincentivos a las empresas para invertir en la transformación tecnológica de sus procesos productivos; esto es, a invertir en innovación, lo cual, a su vez, disminuye la probabilidad de que las firmas puedan insertar en el comercio internacional los productos que ofrecen.

Por lo tanto, si uno de los objetivos de política pública en búsqueda del desarrollo de una economía es la 
transformación tecnológica que permita que las empresas puedan exportar sus productos para lograr mejores condiciones en el sector externo, entonces los gobiernos de los países en desarrollo en general, y de Argentina en particular, deberían hacer énfasis importante en el acceso a los recursos que tienen las empresas pequeñas y medianas.

De esta forma, las firmas podrían acudir a mayores fuentes de financiamiento que les permita invertir en innovación, lo cual causaría un salto tecnológico de las unidades productivas argentinas, que generaría, a su vez, una mayor capacidad de inserción en el comercio exterior.

Según lo planteado por Guzmán, Ocampo y Stiglitz (2017), las políticas de acceso al financiamiento para poder implementar tecnologías propicias para el desarrollo económico y con spillovers positivos sobre el resto de la economía, deberían complementarse con políticas macroeconómicas para impulsar un proceso de desarrollo económico en las economías periféricas como las latinoamericanas.

No obstante, tal y como lo plantea Kulfas (2009), el sistema empresarial argentino posee estructuras de competencia que dan origen a oligopolios y a mayores grados de concentración empresarial, los cuales impiden el surgimiento de nuevas empresas pequeñas y medianas, así como también su óptimo desempeño. De esta manera, siguiendo lo argumentado por Ferraro y Goldstein (2011), muchos de los programas de crédito establecidos por el Gobierno podrían sesgarse hacia firmas de mayor tamaño, reforzando esos niveles de concentración y debilitando su efectividad con relación al objetivo de impulsar al sector de las pequeñas y medianas empresas. Este tema, sin embargo, debería ser objeto de futuras investigaciones.

\section{AGRADECIMIENTOS}

El autor agradece el financiamiento otorgado por la Comisión de Investigaciones Científicas de la Provincia de Buenos Aires mediante la Beca de Entrenamiento 2017 que le permitió desempeñarse como becario de investigación. El autor también agradece los comentarios realizados por Irene Brambilla, los asistentes a la LII Reunión Anual de la Asociación Argentina de Economía Política en Bariloche, Argentina y los evaluadores anónimos. Todos los errores u omisiones son de exclusiva responsabilidad del autor. 


\section{REFERENCIAS}

Arrow, K. J. (1962). Economic Welfare and the Allocation of Resource for Inventions, in the Rate and Direction of Inventive Activity: Economic and Social Factors. New York: National Bureau of Economic Research.

Bebczuk, R. N. (2010). Acceso al financiamiento de las PYMES en Argentina: estado de situación y propuestas de política. Buenos Aires: Cepal.

Brambilla, I., Lederman, D. \& Porto, G. (2012). Exports, Export Destinations, and Skills. American Economic Review, 102(7), 3406-38. https://doi.org/10.1257/ aer.102.7.3406

Brambilla, I., \& Peñaloza, L. (2018). Exportaciones, salarios e innovación tecnológica. Evidencia para Argentina. Económica, 5-21.

Brealey, R., Leland, H. E. \& Pyle, D. H. (1977). Informational Asymmetries, Financial Structure, and Financial Intermediation. The Journal of Finance, 32(2), 371-387. https://doi.org/10.1111/j.1540-6261.1977.tb03277.x

Castillo, D. \& Crespo, P. (2011). La financiación de la innovación empresarial. Revista de Contabilidad y Dirección, 12, 145-164.

Ferraro, C. (comp.) (2011). Eliminando barreras: el financiamiento a las pymes en América Latina (LC/R.2179). Santiago de Chile: Agencia Española de Cooperación Internacional para el Desarrollo AECID/Comisión Económica para América Latina y el Caribe (Cepal).

Ferraro, C. \& Goldstein, E. (2011). Políticas de acceso al financiamiento para las pequeñas y medianas empresas en América Latina. En C. Ferraro (comp.), Eliminando barreras: el financiamiento a las pymes en América Latina. Santiago de Chile: Agencia Española de Cooperación Internacional para el Desarrollo AECID/Comisión Económica para América Latina y el Caribe (Cepal).

Guzmán, M., Ocampo, J. A. \& Stiglitz, J. E. (2017). Real Exchange Rate Policies for Economic Development. Working paper 23868. Cambridge, MA: National Bureau of Economic Research. https://doi.org/10.3386/w23868

Hall, B. H., \& Lerner, J. (2010). The Financing of R\&D and Innovation. In Handbook of the Economics of Innovation (pp. 609-639). North-Holland: Elsevier. https://doi. org/10.1016/S0169-7218(10)01014-2

Kugler, M. \& Verhoogen, E. (2008). The Quality-Complementarity Hypothesis: Theory and Evidence from Colombia. Working paper 14418. Cambridge, MA: National Bureau of Economic Research. https://doi.org/10.3386/w14418 
Kulfas, M. (2009). Las PYMES argentinas en el escenario post convertibilidad. Politicas públicas, situación y perspectivas. Documento de proyecto. Buenos Aires: Cepal.

Marshall, W. (2007). Estructura de mercado, racionamiento crediticio a las pymes, y la banca pública. Economía Informa, 349, 93-104.

Medina, C. \& Espinosa, M. T. (1994). La innovación en las organizaciones modernas. Revista Gestión y Estrategia, 6, 92-97.

Nelson, R. R. (1959). The Simple Economics of Basic Scientific Research. Journal of Political Economy, 67(3), 297-306. https://doi.org/10.1086/258177

Schumpeter, J. A. (1939). Business Cycles. New York: McGraw-Hill.

Stiglitz, J. E. \& Weiss, A. (1981). Credit Rationing in Markets with Imperfect Information. The American Economic Review, 71(3), 393-410.

Ughetto, E. (2009). Industrial Districts and Financial Constraints to Innovation. International Review of Applied Economics, 23(5), 597-624. https://doi. org/10.1080/02692170903007599

Vázquez-Barquero, A. (2000). Desarrollo endógeno y globalización. EURE (Santiago), 26(79), 47-65. https://doi.org/10.4067/S0250-71612000007900003

Verhoogen, E. A. (2008). Trade, Quality Upgrading, and Wage Inequality in the Mexican Manufacturing Sector. The Quarterly Journal of Economics, 123(2), 489-530. https://doi.org/10.1162/qjec.2008.123.2.489

Villar, L., Briozzo, A., Pesce, G. \& Fernández, A. (2016). El rol de la banca pública en el financiamiento a pymes: estudio comparativo para la Argentina y Brasil. Desarrollo y Sociedad, (76), 205-241. https://doi.org/10.13043/dys.76.5

Yoguel, G. \& Boscherini, F. (2001). El desarrollo de las capacidades innovativas de las firmas y el rol del sistema territorial. Desarrollo Económico, 41(161), 37-69. https://doi.org/10.2307/3455964 